\title{
Taste isn't just for taste buds anymore
}

\section{Thomas E. Finger ${ }^{1 *}$ and Sue C. Kinnamon ${ }^{2}$}

\author{
Addresses: ${ }^{1}$ Anschutz Medical Campus, University of Colorado Denver, School of Medicine, Rocky Mountain Taste \& Smell Center, \\ Department of Cell and Developmental Biology, RC-1 South, Room 11118, PO Box 6511, Mail Stop 8108, Aurora, CO 80045, USA; \\ ${ }^{2}$ Anschutz Medical Campus, University of Colorado Denver, School of Medicine, Rocky Mountain Taste \& Smell Center, \\ Department of Otolaryngology, 12700 E 19th Avenue, MS 8606, Aurora, CO 80045, USA \\ *Corresponding author: Thomas E. Finger (tom.finger@ucdenver.edu) \\ Fl000 Biology Reports 20II, 3:20 (doi:10.34I0/B3-20) \\ This is an open-access article distributed under the terms of the Creative Commons Attribution-Non Commercial License \\ (http://creativecommons.org/licenses/by-nc/3.0/legalcode), which permits unrestricted use, distribution, and reproduction in any medium, \\ provided the original work is properly cited. You may not use this work for commercial purposes. \\ The electronic version of this article is the complete one and can be found at: http://fl000.com/reports/b/3/20
}

\begin{abstract}
Taste is a discriminative sense involving specialized receptor cells of the oral cavity (taste buds) and at least two distinct families of $\mathrm{G}$ protein-coupled receptor molecules that detect nutritionally important substances or potential toxins. Yet the receptor mechanisms that drive taste also are utilized by numerous systems throughout the body. How and why these so-called taste receptors are used to regulate digestion and respiration is now a matter of intense study. In this article we provide a historical perspective and an overview of these systems, leading to speculations on directions for further research.
\end{abstract}

\section{Introduction}

The sense of taste is both guardian and guide for our consumption of foods. The sensations of bitter and sour deter us from ingesting potential toxic substances and strong acids, while the preferred qualities of sweet, umami (glutamate), and salty encourage us to eat foods containing carbohydrates, amino acids, and sodium. Taste sensations are mediated by taste buds, which are small clusters of specialized epithelial cells situated within the oropharynx. Over the last two decades, scientists have uncovered the array of $G$ protein-coupled receptor (GPCR) cascades and ion channels that mediate taste signaling. Expression of these receptors and channels is not, however, limited to taste buds. Elements of the taste transduction cascade are expressed by many chemoresponsive epithelial cells scattered within both the alimentary tract and the respiratory passageways. But what are they doing there? Despite the similarities in receptor molecules and transduction cascades, the emerging picture is that the diverse chemoreceptive systems do not all evoke a sensation of taste, but rather serve different functions according to their location.

The sensations of taste can be divided into five distinct qualities: salty, sour, bitter, sweet, and umami (the taste of glutamate). The first two of these are transduced by means of ion channels or gated ion channels expressed in a variety of tissues such as kidney (e.g., [1]). The last three qualities rely on two distinct families of GPCRs first identified in 1999 in taste tissues [2-5]. Two different families of taste receptors are known, T1R and T2R: T1Rs encode the receptor proteins for sweet and umami, and T2Rs do the same for bitter. Despite the difference in underlying qualities detected, the two families of taste receptors utilize similar, if not identical, downstream signaling effectors, most notably the G-protein a-gustducin, phospholipase C $\beta 2$ (PLC $\beta 2$ ), inositol 1,4,5-trisphosphate receptor, type 3 (IP3R3), and the transient receptor potential cation channel TrpM5 (Figure 1). In fact, these signaling components appear to be a hallmark for chemosensory transduction. Indeed, the taste-associated G-protein a-gustducin was among the first proteins involved in a GPCR taste transduction cascade to be identified [6] and is still utilized as a marker for chemosensory cells throughout the body.

Identification of these key molecules in taste transduction led several investigators to the surprising conclusion that these taste transduction mechanisms were widespread 


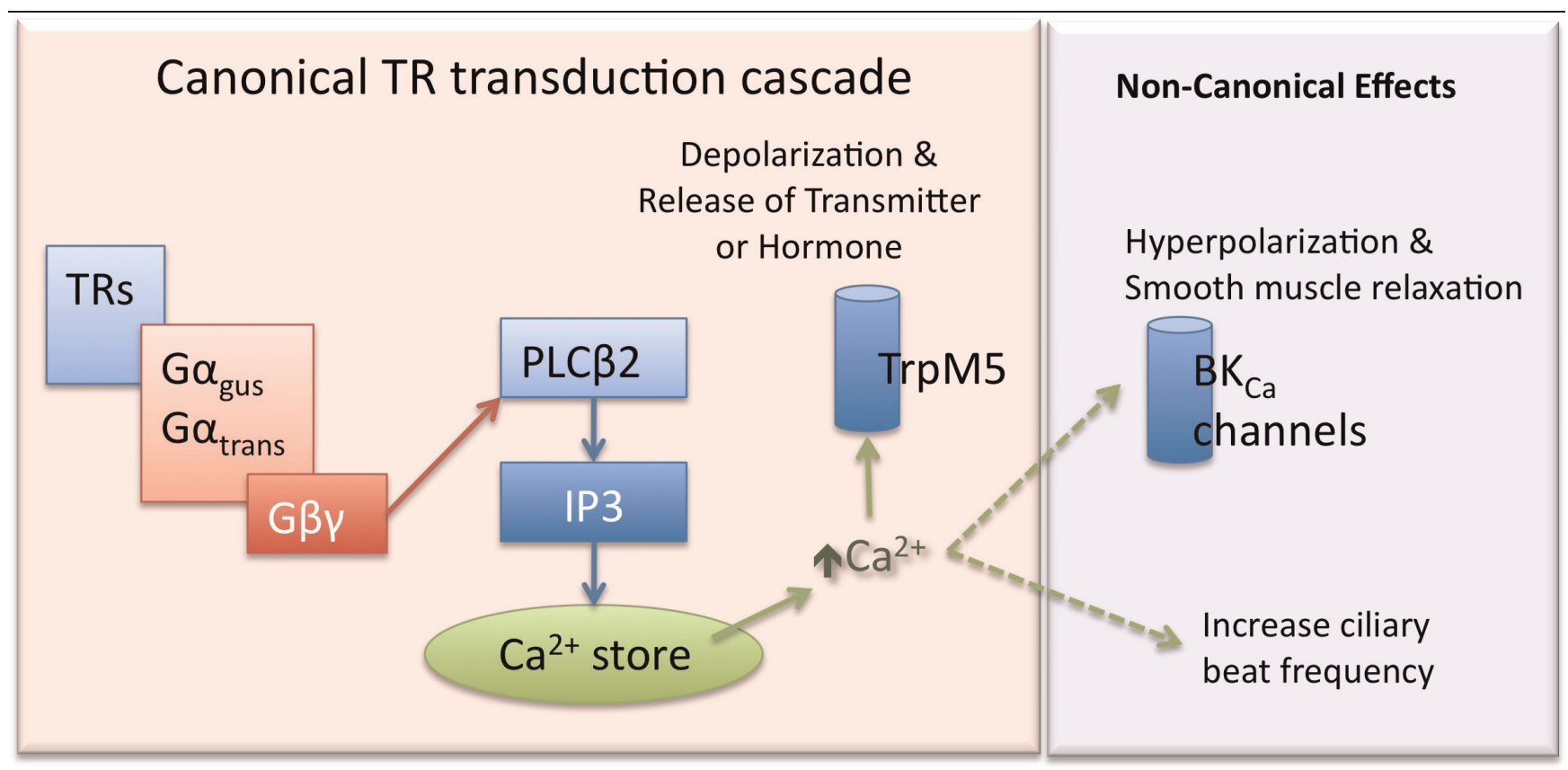

The canonical taste transduction cascade starts with one or more TR families of receptor (either TIR or T2R), which couple to a variety of G-protein $\alpha$ subunits, the best described being gustducin. Receptor activation releases the beta-gamma subunits of the G-protein complex (G $\beta$ ), which activate PLC 32 to generate the second messenger I,4,5-inositol trisphosphate (IP3). The IP3 then triggers the IP3R3 receptor to release $\mathrm{Ca}^{2+}$ from intracellular stores. In taste cells, solitary chemosensory cells and secretory cells, the increased intracellular $\mathrm{Ca}^{2+}$ both activates the TrpM5 channel to depolarize the cell, and facilitates release of transmitters and hormones. In taste buds, the combined depolarization and increased intracellular $\mathrm{Ca}^{2+}$ gates hemichannels to effect release of ATP [38,39]. In other tissues (but not taste buds), the TrpM5-generated depolarization opens voltage-gated $\mathrm{Ca}^{2+}$ channels, which further increases levels of intracellular $\mathrm{Ca}^{2+}$. Some cells express only some elements of the canonical taste transduction cascade and the rise in intracellular $\mathrm{Ca}^{2+}$ acts on other effectors to generate muscle relaxation or changes in ciliary motility. $\mathrm{BK}_{\mathrm{Ca}}$ channel, calcium-activated big potassium channel; $\mathrm{Ga}_{\text {gus }}$, G-protein $\alpha$-gustducin; $\mathrm{Ga}_{\text {trans, }}$ G-protein $\alpha$-transducin; PLC $\beta 2$, phospholipase $C \beta 2$; TrpM5, transient receptor potential cation channel, subfamily M, member 5 .

throughout diverse organ systems, including presumed chemosensory cells of the gut $[7,8]$ and the respiratory tree [9-11] (Figure 2). The wide distribution of presumed chemosensory cells all displaying most elements of the complete taste transduction cascade-from receptor to transduction channel-suggests that these taste-like functions do not all give rise to sensations of taste. For example, the pancreatic release of insulin in response to intake of glucose is partially mediated by detection of the glucose by sweet taste receptor signaling in cells of the intestine [12], but this does not generate a sensation of sweetness. Similarly, accidental inhalation of a beverage into the airways triggers receptors there, but rather than evoking a sensation of taste, the substance is irritating and provokes choking or coughing. The term taste should be reserved for the specific sensory perception originating in taste buds of the oropharynx and transmitted via the facial, glossopharyngeal, or vagus nerves to ultimately reach the gustatory cortex after relays in the brainstem and thalamus. So, although we use the phrases "taste transduction", and "taste receptors" below, we do not mean to imply that the sensations arising from the various systems described are in any way taste. Where we use the term "taste" inappropriately, we include the quotation marks to denote a more casual, tongue-in-cheek (sorry about that) usage.

This article will explore the diversity of organs that express elements of the taste transduction cascade and their functions in each area. Taken together, the findings suggest that the taste transduction cascade is not restricted to taste per se or even to systems regulating food intake. The receptors mediating taste transduction evolved early in the vertebrate lineage [13], and were adopted widely as a chemodetection system in a variety of organ systems. Questions still remain as to what the natural ligands are for many of the nongustatory functions of the "taste" transduction system [14].

\section{"Taste" in the gut}

The first indication that elements of the taste transduction cascade might exist outside of the mouth was the report in 1996 of the expression of the taste signaling-associated 
G-protein a-gustducin in brush cells of the stomach and intestine [7]. Brush cells are tall, columnar epithelial cells that display a distinctive tuft of stiff microvilli at their apex. Based on morphological features, it was suggested that these cells might have a chemosensory function [15], but the finding of gustducin and later even "taste" receptors $[8,16-19]$ and TrpM5 [20] in these cells confirmed this early speculation. More recent studies reveal that taste transduction-related signaling occurs in a variety of cell types throughout much of the gut from the stomach to the large intestine (e.g., [20]) (Figure 2). Despite the widespread expression of taste-related signaling components in the gut, they are not necessary for the post-ingestive hedonic reward of ingested sweet substances [21], but rather serve digestive functions.

\section{The good, the bad, and the tasty}

Members of the T1R family of taste receptors combine in taste cells to form either a sweet receptor (T1R2 + T1R3) or an umami (glutamate) receptor (T1R1 + T1R3). Both receptors signal macronutrients necessary for survival (a carbohydrate energy source and amino acids, respectively) so it is reasonable to consider that these receptors may respond to similar ligands in the gut to regulate digestive functions. Indeed, secretory cells of the stomach express T1R family receptors $[18,22]$ and release the appetite-inducing peptide ghrelin in response to activation by the appropriate ligand. Accordingly, when either sweets or glutamate-rich foods first enter the stomach, they cause the release of ghrelin, which stimulates further food intake.

Farther down the gastrointestinal tract, sweet substances are detected by enteroendocrine cells that secrete the glucagon-like peptide GLP-1. This hormone is an incretin, which enhances release of insulin from pancreatic $\beta$-cells. The presence of circulating insulin results in uptake of glucose from the bloodstream by diverse tissues. Activation of the sweet receptors in the gut also drives insertion of the glucose transporters SGLT1 (sodium-glucose cotransporter 1) and GLUT2 (facilitated glucose transporter 2), in the apical membrane of cells of the intestinal epithelium, thereby facilitating uptake of glucose in the upper parts of the gastrointestinal tract $[17,23]$.

While the presence of T1R-class receptors for macronutrients in the gut is an obvious means to regulate digestive functions, the reason for the presence of $T 2 R$ bitter receptors seems less clear. One clue comes from the observation that activation of $\mathrm{T} 2 \mathrm{R}$ receptors in an enteroendocrine cell line (STC-1 cells) results in release of the peptide hormone cholcystokinin (CCK), which can reduce gut motility. So, intake of a potential toxin that activates the T2R pathway should decrease the rate at which food passes through the stomach and lower the drive for continued eating (presumably this response inhibits further ingestion of toxin) [24]. The bitter-tasting ligand induces enteroendocrine cells to release CCK, which in turn excites sensory nerve processes of the vagus nerve to carry the signal to the brain [25], suggesting that the regulation of food intake involves both peripheral and central controls. However, a recent study [26] suggests that the lower gut motility following intake of bitter substances is not purely dependent on $\mathrm{T} 2 \mathrm{R} /$ gustducin signaling or CCK.

An alternative explanation is that the CCK-secreting enteroendocrine cells may be involved in a paracrine signaling system that reduces transfer of toxic substances from the gut into the circulation. This is supported by a study showing that CCK (released in response to bittertasting ligands) then acts on CCK2 receptors [27] on nearby enterocytes to increase expression of the transporter ABCB1 (ATP-binding cassette B1), which pumps toxins or unwanted substances out of the cytoplasm. In this way, activation of the T2R signaling network indirectly increases elimination of absorbed toxins from gut epithelium before the toxins can enter circulation.

Lower in the gut, activation of $\mathrm{T} 2 \mathrm{R}$ receptors has a different effect. When some bitter-tasting ligands are applied to the colonic epithelium, they induce the secretion of anions, which leads to fluid secretion by the epithelium [28]. This induced efflux of fluids is likely to flush out any noxious irritant from the colon.

\section{"Taste" in the airways}

The first description of taste-related signaling components in the airway was a report by Zancanaro and colleagues describing the presence of gustducin-expressing cells in the vomeronasal organ [29], which is a specialized part of the olfactory system found in many vertebrates but absent in adult humans. The gustducin-expressing cells in the vomeronasal organ are scattered epithelial cells mainly distributed along the incoming ducts of the organ and within the non-sensory epithelium of the organ itself. The morphology of these cells is similar to chemosensory cells scattered within the epidermis of fishes as first described by Mary Whitear in the 1960s [30] when she referred to them as solitary chemosensory cells (SCCs).

Subsequently, we and others showed that SCCs are present throughout the upper respiratory system and express the entire suite of taste-related signaling molecules, including T2R receptors, PLC $\beta 2$, gustducin, and the transduction channel TrpM5 $[9,20]$. Finger et al. [9] demonstrated that the taste signaling cascade is necessary 
Figure 2. Sites in the body where cells express the canonical taste receptor cascade

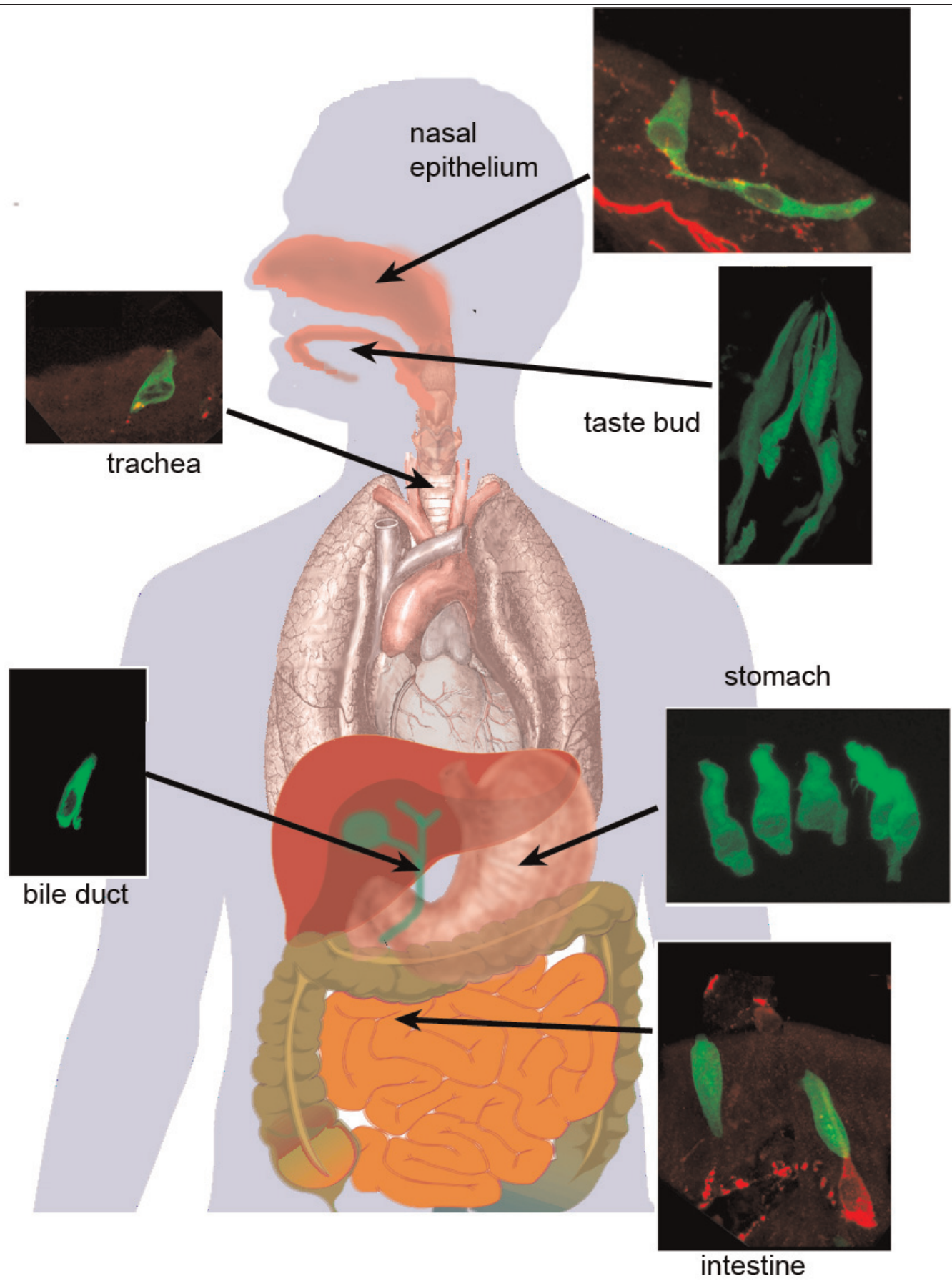

Taste buds comprise three types of elongated cells, one of which (type II/receptor cells, identified by green fluorescence) expresses the taste receptor (TR)-mediated transduction cascade culminating in activation of TrpM5. In the nasal cavity (top right), solitary chemosensory cells express the "taste" transduction cascade and synapse onto nerve fibers (red) arising from the trigeminal nerve [9]. In the trachea (upper left), the "taste"-like cells are brush cells, which release acetylcholine upon stimulation [40]. Some also make contacts with sensory nerve fibers (red) from the vagus nerve. In the stomach (center lower right), a variety of enteroendocrine cells express elements of the taste transduction cascade $[18,20,22]$ and release into the gut a variety of peptide hormones. Numerous brush cells in the gall bladder and bile ducts express the canonical taste transduction cascade [15,20]; their function is unknown. In the upper part of the small intestine (e.g., duodenum, lower right), a variety of enteroendocrine cells express taste receptors and the associated downstream transduction cascade $[16,17]$. Some of these extend into the intestinal lumen while others do not. When activated, these cells release a variety of gut peptides as discussed in the main text. Micrographs courtesy of Dr. Marco Tizzano. 
for activation of the SCCs. Since the SCCs synapse onto polymodal pain fibers of the trigeminal nerve, activation of the SCCs by bitter ligands evokes trigeminallymediated reflex changes in respiration. So inhalation of a toxin that activates $\mathrm{T} 2 \mathrm{R}$ receptors will be irritating and will provoke reflex changes in respiration [11] - not a sensation of taste. More recently, we showed that even some bacterial metabolites and signal molecules can activate the nasal SCCs and trigeminal nerve [11]. Since the activated trigeminal nerve fibers release peptide modulators (e.g., substance P or calcitonin gene-related peptide), this causes local neurogenic inflammation of the respiratory epithelium. In this way, SCCs act not only as sentinels warning against inhalation of irritants, but also as guardians capable of activating the innate immune system to the presence of potentially damaging toxins or pathogens.

In all of the examples presented so far, the taste signaling cascade is used to detect elements in the lumen of an organ (tongue, gut, respiratory passages), and to generate an intracellular cascade to effect release of a neurotransmitter or hormone to signal to other cells in the body. Two recent reports on the expression of "taste" receptors in the airways indicate that taste receptor signaling may also operate in a cell-autonomous fashion, that is, detection of the chemical directly affects function of the responsive cell.

The first such report of a cell-autonomous effect of T2R activation was in ciliated cells of human lower airways [32]. Cultured human airway epithelium expresses some T2Rs along with associated downstream elements. Curiously though, the T2Rs are present on the cilia of the ciliated epithelial cells with PLC $\beta 2$ situated where the cilia insert into the cell body. In this scenario, the T2Rmediated increase in intracellular $\mathrm{Ca}^{2+}$ causes an increase in ciliary beat frequency (Figure 1), which the authors suggest would serve to sweep irritants away from the surface of the cell. Whereas T2Rs can be detected in cultured human airway cells, they are not detected in the lower airways of mice [33]. Whether this represents a species difference or the difference between in vivo (mouse) and in vitro (human) states remains to be determined.

The second report of T2Rs directing function within an airway cell came from Deshpande and colleagues [34] showing that smooth muscle cells of human airways express T2R (bitter) taste receptors along with gustducin and some components of the taste-associated PLC signaling cascade. Application of various bitter-tasting substances to cultured human airway smooth muscle cells produces PLC-dependent increases in intracellular
$\mathrm{Ca}^{2+}$ as would be typical of taste cells or SCCs. Surprisingly, these increases in intracellular $\mathrm{Ca}^{2+}$ are reported to cause relaxation rather than contraction of muscle, which is what is normally seen with increases in intracellular $\mathrm{Ca}^{2+}$. This apparently paradoxical effect in the airway smooth muscle cells is attributed to the proximity of the $\mathrm{T} 2 \mathrm{R}$ receptor complex to calciumactivated big potassium $\left(\mathrm{BK}_{\mathrm{Ca}}\right)$ channels (Figure 1), which open in response to increased intracellular $\mathrm{Ca}^{2+}$. Opening of the $\mathrm{BK}_{\mathrm{Ca}}$ channels directly hyperpolarizes the muscle cell leading to relaxation. In contrast, in taste cells and SCCs, activation of the T2R receptor causes increased intracellular $\mathrm{Ca}^{2+}$, as in the airway smooth muscle, but in the sensory cells, the increased intracellular $\mathrm{Ca}^{2+}$ triggers the transduction channel TrpM5 to depolarize the cell and evoke transmitter release. Thus in different signaling contexts, activation of the same receptor can produce opposite cellular-level effects. It should be noted, however, that the findings of Deshpande and colleagues [34] have since been questioned in terms of specificity and mechanism; see $[35,36]$.

\section{Conclusions and future directions}

The widespread expression of elements of the "taste" transduction cascade in numerous tissues of the body points out the necessity for caution in attributing a physiological function to a system based solely on expression of a gene product. Activation of taste receptors in taste buds does not give rise to the same sensation as activation of the identical receptors in the airways or gut. The physiological function of a receptor, or a Trp channel, or a G-protein, makes sense only in the context in which it is expressed. So despite the title of this article, "taste" receptors of the airway or gut really should not be thought of as an internal sense of taste, but rather as an entirely different chemoreceptor system.

While it is evident that "taste" receptors and their associated downstream signaling components are widely dispersed in diverse organ systems, the function of the receptors in many tissues remains unclear despite recent advances. For example, why should there be such a prevalence of taste receptor-expressing brush cells in the bile ducts [31,37]? The composition of the fluid in the bile ducts is dictated by secretions of the liver, pancreas, and gall bladder, so why is it necessary to diligently monitor the composition of the biliary fluids as they move from gall bladder to intestine?

Similarly enigmatic are the reported effects of T2R (bitter) agonists on contractile elements of both the airway and the gut. In the trachea, T2R agonists cause muscle relaxation (see above) but it is not clear how a bitter substance would have access to the smooth muscle 
cells of the trachea under physiological conditions. The smooth muscle of the trachea is buried beneath a relatively tight airway epithelium, and it is not obvious how an inhaled bitter substance would penetrate the epithelium to access $\mathrm{T} 2 \mathrm{R}$ receptors on the muscle. Similarly, the inhibition of smooth muscle contractility by T2R agonists in the stomach is not mediated by any of the peptides released by enterochromaffin cells of the gut and may not even be mediated by $\mathrm{T} 2 \mathrm{R}$ receptors. These and other nonspecific effects of bitter ligands emphasize the need to utilize either pharmacological agents or, better still, knockout animals to establish the specificity of transduction pathways and receptors for all physiological effects. Hopefully future research will solve these enigmas.

\section{Abbreviations}

$\mathrm{BK}_{\mathrm{Ca}}$ channel, calcium-activated big potassium channel; CCK, cholcystokinin; GPCR, G protein-coupled receptor; PLC, phospholipase C; SCC, solitary chemosensory cells; TrpM5, transient receptor potential cation channel, subfamily $\mathrm{M}$, member 5 .

\section{Competing interests}

The authors declare that they have no competing interests.

\section{Acknowledgements}

This work was supported by grants from the National Institute on Deafness and Other Communication Disorders (NIDCD) of the National Institutes of Health: P30 DC04657, R01DC009820, R01 DC007495, RO1 DC006021, \& RO1DC00766.

\section{References}

I. Schild L: The epithelial sodium channel and the control of sodium balance. Biochim Biophys Acta 2010, I 802: I I59-65.

FI000 Factor 6

Evaluated by Sue Kinnamon 18 Aug 2011

2. Hoon MA, Adler E, Lindemeier J, Battey JF, Ryba NJ, Zuker CS: Putative mammalian taste receptors: a class of taste-specific GPCRs with distinct topographic selectivity. Cell 1999, 96:54I-5I.

3. Adler E, Hoon MA, Mueller KL, Chandrashekar J, Ryba NJ, Zuker CS: A novel family of mammalian taste receptors [see comments]. Cell 2000, 100:693-702.

4. Nelson G, Hoon MA, Chandrashekar J, Zhang Y, Ryba NJ, Zuker CS: Mammalian sweet taste receptors. Cell 2001, 106:381-90.

FI000 Factor 8

Evaluated by Stephen Roper 14 Oct 2001

5. Nelson G, Chandrashekar J, Hoon MA, Feng L, Zhao G, Ryba NJ, Zuker CS: An amino-acid taste receptor. Nature 2002, 416:199-202.

FI000 Factor 13

Evaluated by Roger Hardie 19 Mar 2002, Mark Nelson 02 Apr 2002,

Bruce Conklin 09 Apr 2002, Frank Zufall 10 Apr 2002
6. McLaughlin SK, McKinnon PJ, Margolskee RF: Gustducin is a tastecell-specific $\mathbf{G}$ protein closely related to the transducins. Nature 1992, 357:563-9.

7. Hofer D, Puschel B, Drenckhahn D: Taste receptor-like cells in the rat gut identified by expression of alpha-gustducin. Proc Natl Acad Sci U S A 1996, 93:6631-4.

8. Wu SV, Rozengurt N, Yang M, Young SH, Sinnett-Smith J, Rozengurt E: Expression of bitter taste receptors of the $T 2 R$ family in the gastrointestinal tract and enteroendocrine STC-I cells. Proc Natl Acad Sci U S A 2002, 99:2392-7.

9. Finger TE, Böttger B, Hansen A, Anderson KT, Alimohammadi H, Silver WL: Solitary chemoreceptor cells in the nasal cavity serve as sentinels of respiration. Proc Natl Acad Sci U S A 2003, 100:898|-6.

10. Sbarbati A, Merigo F, Benati D, Tizzano M, Bernardi P, Crescimanno $C$, Osculati $F$ : Identification and characterization of a specific sensory epithelium in the rat larynx. J Comp Neurol 2004, 475: |88-20|.

II. Tizzano M, Gulbransen BD, Vandenbeuch A, Clapp TR, Herman JP, Sibhatu HM, Churchill ME, Silver WL, Kinnamon SC, Finger TE: Nasal chemosensory cells use bitter taste signaling to detect irritants and bacterial signals. Proc Natl Acad Sci U S A 20I0, 107:3210-5.

12. Jang HJ, Kokrashvili Z, Theodorakis MJ, Carlson OD, Kim BJ, Zhou J, Kim HH, Xu X, Chan SL, Juhaszova M, Bernier M, Mosinger B, Margolskee RF, Egan JM: Gut-expressed gustducin and taste receptors regulate secretion of glucagon-like peptide-I. Proc Natl Acad Sci U S A 2007, I 04:15069-74.

I3. Oike H, Nagai T, Furuyama A, Okada S, Aihara Y, Ishimaru Y, Marui T, Matsumoto I, Misaka T, Abe K: Characterization of ligands for fish taste receptors. J Neurosci 2007, 27:5584-92.

FI000 Factor 6

Evaluated by Sue Kinnamon 31 May 2007

14. Gulbransen BD, Clapp TR, Finger TE, Kinnamon SC: Nasal solitary chemoreceptor cell responses to bitter and trigeminal stimulants in vitro. J Neurophysiol 2008, 99:2929-37.

15. Fujita T: Taste cells in the gut and on the tongue. Their common, paraneuronal features. Physiol Behav 1991, 49:883-5.

16. Rozengurt E: Taste receptors in the gastrointestinal tract. I. Bitter taste receptors and alpha-gustducin in the mammalian gut. Am J Physiol Gastrointest Liver Physiol 2006, 29 I:GI7I-7.

I7. Margolskee RF, Dyer J, Kokrashvili Z, Salmon KS, llegems E, Daly K, Maillet EL, Ninomiya Y, Mosinger B, Shirazi-Beechey SP: TIR3 and gustducin in gut sense sugars to regulate expression of $\mathrm{Na}+$ glucose cotransporter I. Proc Natl Acad Sci U S A 2007, I 04: | 5075-80.

18. Hass N, Schwarzenbacher K, Breer H: TIR3 is expressed in brush cells and ghrelin-producing cells of murine stomach. Cell Tissue Res 2010, 339:493-504.

FI000 Factor 6

Evaluated by Tom Finger 18 Aug 2011

19. Nakamura E, Hasumura M, San Gabriel A, Uneyama H, Torii K: New frontiers in gut nutrient sensor research: luminal glutamatesensing cells in rat gastric mucosa. J Pharmacol Sci 2010, I | 2: 13-8.

20. Kaske S, Krasteva G, Konig P, Kummer W, Hofmann T, Gudermann T, Chubanov V: TRPM5, a taste-signaling transient receptor potential ion-channel, is a ubiquitous signaling component in chemosensory cells. BMC Neurosci 2007, 8:49.

21. Sclafani A, Glass DS, Margolskee RF, Glendinning JI: Gut TIR3 sweet taste receptors do not mediate sucrose-conditioned flavor preferences in mice. Am J Physiol Regul Integr Comp Physiol 2010, 299:RI643-50.

FI000 Factor 8

Evaluated by Tom Finger 18 Aug 2011

22. Hass N, Schwarzenbacher $\mathrm{K}$, Breer $\mathrm{H}$ : A cluster of gustducinexpressing cells in the mouse stomach associated with two 
distinct populations of enteroendocrine cells. Histochem $\mathrm{Cell}$ Biol 2007, | 28:457-7|.

23. Mace OJ, Affleck J, Patel N, Kellett GL: Sweet taste receptors in rat small intestine stimulate glucose absorption through apical GLUT2. J Physiol 2007, 582:379-92.

24. Glendinning JI, Yiin YM, Ackroff K, Sclafani A: Intragastric infusion of denatonium conditions flavor aversions and delays gastric emptying in rodents. Physiol Behav 2008, 93:757-65.

25. Hao S, Sternini C, Raybould HE: Role of CCKI and Y2 receptors in activation of hindbrain neurons induced by intragastric administration of bitter taste receptor ligands. Am J Physiol Regul Integr Comp Physiol 2008, 294:R33-8.

FI000 Factor 8

Evaluated by Tom Finger 18 Aug 2011

26. Janssen S, Laermans J, Verhulst PJ, Thijs T, Tack J, Depoortere I: Bitter taste receptors and $\alpha$-gustducin regulate the secretion of ghrelin with functional effects on food intake and gastric emptying. Proc Natl Acad Sci U S A 20I I, I 08:2094-9.

FI000 Factor 7

Evaluated by Masayasu Kojima I0 Feb 20 I I, Tom Finger I8 Aug 201 I

27. Jeon TI, Seo YK, Osborne TF: Gut bitter taste receptor signaling induces $A B C B$ I through a mechanism involving CCK. Biochem J 20I I, 438:33-7.

FI000 Factor 8

Evaluated by Sue Kinnamon 18 Aug 2011

28. Kaji I, Karaki S, Fukami Y, Terasaki M, Kuwahara A: Secretory effects of a luminal bitter tastant and expressions of bitter taste receptors, T2Rs, in the human and rat large intestine. Am J Physiol Gastrointest Liver Physiol 2009, 296:G97I-8I.

FI000 Factor 6

Evaluated by Sue Kinnamon 18 Aug 201I

29. Zancanaro C, Caretta CM, Merigo F, Cavaggioni A, Osculati F: alphaGustducin expression in the vomeronasal organ of the mouse. Eur J Neurosci 1999, I I:4473-5.

30. Whitear M: Solitary Chemoreceptor Cells. In Chemoreception in Fishes. 2nd edition. Edited by Hara TJ. London: Elsevier Press; 1992: 103-125.

31. Tizzano M, Kokrashvili Z, Mosinger B, Vijayaraghavan S, Margolskee RF, Finger TE: Solitary Chemosensory Cells (SCCs) in the Pancreas. Chem Senses 2009, 34:A82-A3.
32. Shah AS, Ben-Shahar Y, Moninger TO, Kline JN, Welsh MJ: Motile cilia of human airway epithelia are chemosensory. Science 2009, 325: || $3 \mid-4$.

FI000 Factor II

Evaluated by Sue Kinnamon 04 Sep 2009, Arturo Alvarez-Buylla 14 Sep 2009, Stephen Roper 20 Jan 2011

33. Tizzano M, Cristofoletti $M$, Sbarbati A, Finger TE: Expression of taste receptors in solitary chemosensory cells of rodent airways. BMC Pulm Med 201 I, I I:3.

34. Deshpande DA, Wang WC, Mcllmoyle EL, Robinett KS, Schillinger RM, An SS, Sham JS, Liggett SB: Bitter taste receptors on airway smooth muscle bronchodilate by localized calcium signaling and reverse obstruction. Nat Med 2010, 16:1299-304.

FI000 Factor 19

Evaluated by Domenico Spina 18 Nov 2010, Bernd Nilius 19 Nov 2010 , Philip Murphy 29 Nov 2010, James Martin 02 Dec 2010, Michael Caplan 14 Apr 20II

35. Morice $\mathrm{AH}$, Bennett RT, Chaudhry MA, Cowen ME, Griffin SC, Loubani M: Effect of bitter tastants on human bronchi. Nat Med 20II, I 7:775.

36. Belvisi MG, Dale N, Birrell MA, Canning BJ: Bronchodilator activity of bitter tastants in human tissue. Nat Med 20II, I 7:776.

37. Höfer D, Drenckhahn D: Identification of the taste cell G-protein, $\alpha$-gustducin, in brush cells of the rat pancreatic duct system. Histochem Cell Biol 1998, I I0:303-9.

38. Huang YJ, Maruyama Y, Dvoryanchikov G, Pereira E, Chaudhari N, Roper SD: The role of pannexin I hemichannels in ATP release and cell-cell communication in mouse taste buds. ProC Natl Acad Sci U S A 2007, 104:6436-4I.

FI000 Factor 8

Evaluated by Sue Kinnamon 10 Apr 2007

39. Romanov RA, Rogachevskaja OA, Bystrova MF, Jiang $P$, Margolskee RF, Kolesnikov SS: Afferent neurotransmission mediated by hemichannels in mammalian taste cells. EMBO J 2007, 26:657-67.

FI000 Factor 6

Evaluated by Sue Kinnamon 06 Mar 2007

40. Krasteva G, Canning BJ, Hartmann P, Veres TZ, Papadakis T, Muhlfeld C, Schliecker K, Tallini YN, Braun A, Hackstein H, Baal N, Weihe E, Schutz B, Kotlikoff M, Ibanez-Tallon I, Kummer W: Cholinergic chemosensory cells in the trachea regulate breathing. Proc Natl Acad Sci U S A 20I I, I 08:9478-83.

FI000 Factor II

Evaluated by Sue Kinnamon 07 Jun 201 I, Tom Finger 30 Jun 201 I 